\title{
Automatic segmentation and volumetric assessment of internal organs and fatty tissue: what are the benefits?
}

\author{
Fritz Schick ${ }^{1}$ (D)
}

Received: 8 November 2021 / Revised: 3 December 2021 / Accepted: 5 December 2021 / Published online: 17 December 2021

(c) The Author(s) 2021

The most important goal of traditional medical imaging in the clinic is to show pathological changes on projection or slice images. The crucial criterion for the quality of the images, apart from spatial resolution, is usually the contrast between normal and pathologically changed tissue.

All currently available imaging modalities, including $\mathrm{X}$-ray technology, ultrasound, magnetic resonance and positron emission tomography, have developed very rapidly over the past decades. Not only has the quality of the images improved while examination times have become shorter, but new aspects of the evaluation of the image data have also come into focus.

Particularly in the case of MRI, which in the past was often unable to exploit its full potential in the usual examination times of about 30-45 min due to relatively long measuring times for each imaging sequence, the modern methods with "massive parallel imaging", [1] "compressed sensing" [2] and/or "finger printing" [3] are of benefit: it is now possible to perform comprehensive multi-parametric and quantitative tissue analyses in tolerable examination times. Instead of one "contrast weighting", raw data for several quantifiable tissue properties ( $11, \mathrm{~T} 2, \mathrm{~T} 2 *$, fat content, water diffusion, etc.) can now be collected in the same examination time. Furthermore, modern MRI systems allow the acquisition of high-resolution isotropic image data sets of the entire body or at least of the body trunk, which contain a large amount of morphological information.

The evaluation of anatomical-morphological information in 3D image data sets was initially limited to the manual determination of obvious disease-relevant information, e.g. for assessing the size of tumours or metastases in staging or for monitoring the course of disease under therapy [4]. While the (maximum) diameter of an anatomical structure

\section{Fritz Schick}

fritz.schick@med.uni-tuebingen.de

1 Department of Radiology, Section of Experimental Radiology, University Tübingen, Tuebingen, Germany could be determined rather quickly, it was much more timeconsuming to perform volumetric analyses, as several slices had to be evaluated manually for this purpose. Somewhat delayed to the development of MR acquisition methods for high-resolution 3D datasets, automatic or at least semi-automatic segmentation methods were developed and used in many studies [5]. With the introduction of modern artificial intelligence (AI) methods, the possibilities for reliable organ segmentation from MRI datasets have improved significantly in recent years [6]. Only with the help of these methods has it now become feasible to evaluate individual anatomical structures in thousands of 3D data sets from large population based cohort studies (e.g., UK Biobank [7] or German National Cohort [8]) with manageable effort. With these data, on the one hand, correlations between anatomical features, genetic characteristics, life circumstances (e.g., nutrition and physical activity) and physical condition (physical fitness and diseases) can be explored. On the other hand, the results of volumetric assessment of organs in cohort studies are also very well suited for working out standard values and normal value ranges for different population groups depending on age and gender.

An important question is, of course, whether these volumetric data can also be used as indicators of disease in individual patients. The examination conditions (resting position, relatively uniform spatial sensitivity with modern multi-array head coils) and evaluation conditions (few tissue classes with relatively consistent spatial distribution) are quite favourable for MRI examinations of the brain. In addition, there are many institutions involved in neuroscience. Therefore, applications of volumetric assessment of brain structures [9] are certainly the most advanced and already well-studied for clinical questions [10].

The severity and time course of white and grey matter loss in different brain areas can provide differential diagnostic clues in diseases [11] and quantify the development of atrophy [12]. Deviations from normal age-related atrophy 
can be detected and effects of therapeutic interventions can be accurately measured.

For the work presented in many publications "homemade" segmentation algorithms have been applied, which are not easily applicable by the reader. Often the AI methods are trained with specific MRI images (in terms of contrast weighting, geometric imaging parameters, and coil arrangements) and a general applicability is not certain even if the algorithm is published. Recently, however, some MR vendors offer complete packages of sequences and segmentation tools that work reliably (e.g., for automatic segmentation of the liver). In neuro MRI studies, free software for segmentation (e.g., SPM, Wellcome Centre for Human Neuroimaging, UCL Neurology, London, UK) is available, which is used by many scientific groups and which can also be safely combined with clinical acquisition sequences. Furthermore, there is commercial support especially for post-processing of data from cohort studies from companies such as AMRA Medical (Linköping, Sweden).

To better assess the clinical relevance of automated segmentation and volumetric assessment of organ systems in the trunk of the body, some information about the significance of organ volume in diseases is provided in the following:

\section{Lungs}

The individual lung volume is of course dependent on the breathing position and thus variable. Thus, consistent examination protocols are necessary for both reference and comparative measurements. Congenital diseases such as diaphragmatic hernias or bronchopulmonary malformations are often associated with a reduced lung volume. To obtain normal values in early childhood development, a number of lung volume examinations have been performed in foetuses depending on gestational age, but the results have not been entirely consistent [13]. In adults, acquired restrictive lung diseases such as pulmonary fibrosis or sarcoidosis can lead to reduced lung volume. In contrast, emphysema and COPD show overinflation of the lungs and thus often an increase in lung volume [14].

\section{Heart}

In cardiac patients (e.g., with dilatation or hypertrophy of the myocardium), MRI scans are performed with ECG synchronisation. Imaging in multiple cardiac phases allows assessment of the thickness of myocardial walls, systolic and diastolic blood volumes and derived functional parameters [15, 16] (see upper row of images in Fig. 1). The usual MRI data sets of the trunk are acquired without ECG triggering and are, therefore, usually not evaluable with regard to cardiac size and function. However, modern MRI procedures have already been described that can reconstruct respiratory and cardiac phase-dependent MRI images even without external triggering [17], as well as automated procedures for determining cardiac contours [18].

\section{Liver}

In healthy liver, the organ volume can be considered a good parameter for the function of the organ. Liver size with normal value ranges has been investigated in CT studies, and formulas for "normal liver volume" as a function of body size have been given [19]. Those have been further refined and also adapted for different ethnicities [20, 21]. Parenchymal liver diseases such as steatosis, iron overload or cirrhosis are reported to significantly increase liver volume compared to normal values [21]. It should be noted, however, that the functionally active fraction of liver volume becomes smaller in cases with restrictive remodelling processes (hepatic fibrosis and cirrhosis) and must be determined separately by segmentation of the internal hepatic structures [22] Lifestyle changes in patients with steatosis led to a significant reduction in liver volume in parallel with a reduction in liver fat content [23, 24]. Particularly important clinical significance is given to the functional liver volume still available after partial resection (in the case of tumours or transplants), which must be taken into account when planning surgical procedures [25]

\section{Spleen}

Enlarged spleen (splenomegaly) is often caused by liver disease associated with hypertension in the portal system. The relationship between the degree of liver fibrosis or portal hypertension and spleen volume has recently been quantitatively studied in a large number of patients [26]. Splenomegaly with often markedly increased volume compared to normal is also observed in some infectious diseases (viral diseases such as EBV and CMV; but also in malaria or toxoplasmosis) and in haematological (thalassaemia, sickle cell anaemia) or immunological (juvenile arthritis, lupus erythematosus) disorders [27].

\section{Pancreas}

It has been reported that pancreatic volume tends to be reduced in both type I [28] and type 2 diabetes [29] compared with healthy individuals. In acute pancreatitis, an increased volume of the organ is observed [30], but after several acute episodes of pancreatitis have subsided, the 
Fig. 1 Shows in the top row two short-axis views of the heart in diastole (left) and systole (right). The myocardium of the left ventricle is segmented and coloured purple, areas of epi-I pericardial fat are depicted in orange. The middle row shows MR images with segmentation of internal organs as liver (green), spleen (light purple) and left (brown) and right (blue) kidneys. The two images in the bottom row highlight the subcutaneous fat (yellow) and visceral fat (red)
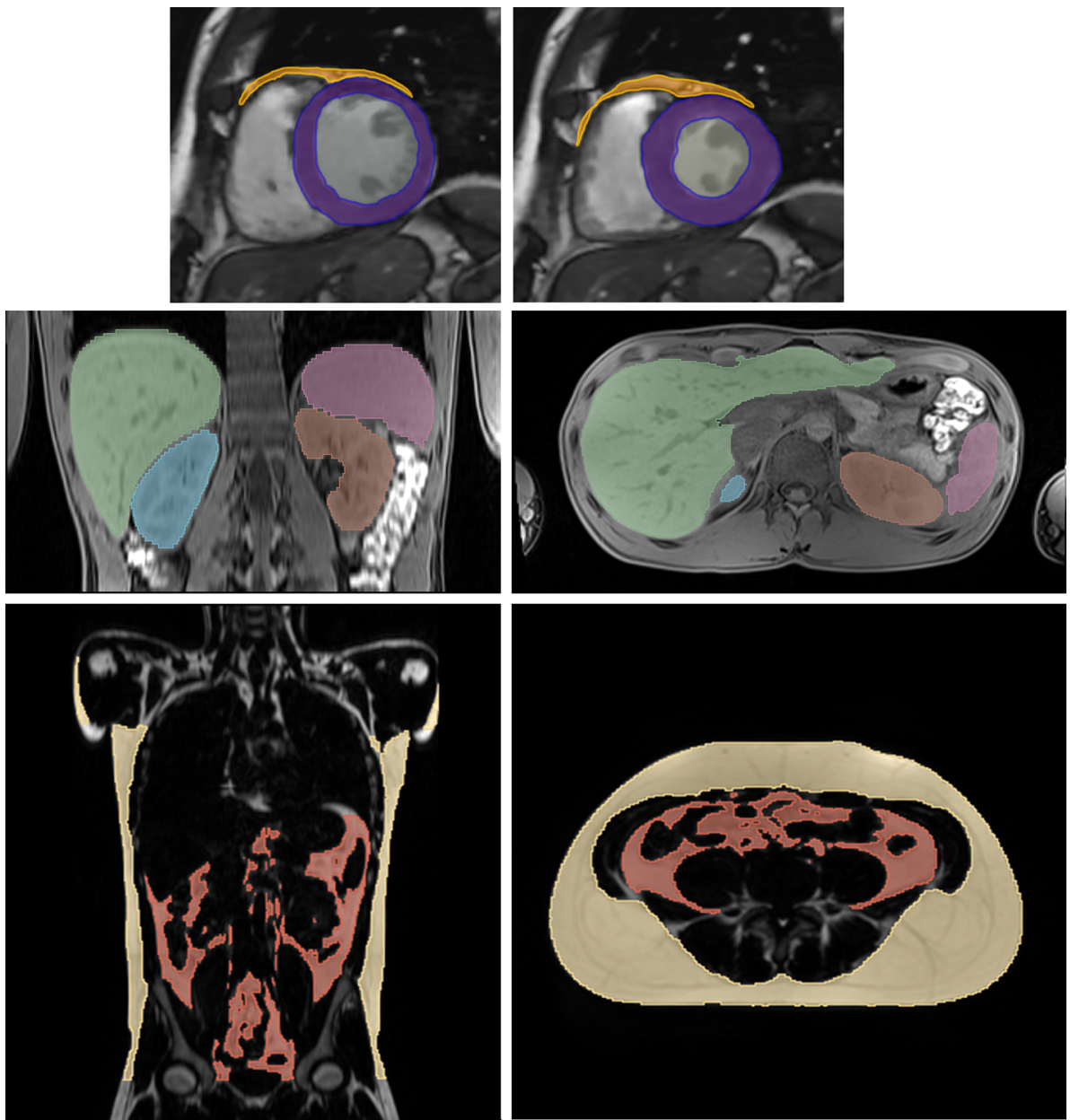

pancreas volume is often significantly reduced [31]. Manual or automatic segmentation of the pancreas on CT or MR images in the case of (peripheral) fatty infiltration is hardly reliable [32]. Fatty infiltration of the pancreas is particularly common in cystic fibrosis, and differentiation from the surrounding fatty tissue is then often very difficult [33].

\section{Kidneys}

In the kidney, the two main components, cortex and medulla, can usually be reliably segmented separately in 3D data sets from CT scans [34] and MRI scans [35]. The volume of the renal cortex in particular decreases significantly with age, while the volume of the renal medulla remains constant or even increases [34]. Deviations from normal values are seen on the one hand in congenital aplasia or hypoplasia of the kidneys, but also in acquired malfunctions. Enlarged, swollen kidneys occur in acute inflammatory processes (pyelonephritis) and in chronic diseases in early stages, while longterm kidney diseases (e.g., diabetic kidney) potentially cause fibrosis with a loss of function and a reduction in volume
[36]. A disease pattern that is particularly frequently examined volumetrically using MRI is hereditary autosomal dominant polycystic kidney disease (ADPKD) [37].

\section{Adipose tissue (subcutaneous, visceral, epi- and pericardial)}

Over the past 2 decades, many studies on the role of body fat in the development of metabolic and cardiovascular disease have been conducted. It has been demonstrated that it is not so much the total amount of adipose tissue as the distribution of adipose tissue in different compartments that plays an important role [38]. While subcutaneous adipose tissue contributes little to the development of metabolic-associated diseases, the amount of visceral fat located around abdominal organs, with its propensity for chronic inflammation, correlates significantly with reduced insulin action [39]. Larger amounts of visceral fat and also of fat in the thoracic cavity surrounding the myocardium (epicardial and pericardial fat, which are difficult to distinguish in MR images because they are separated by only a thin layer) have been identified 
as risk factors for cardiovascular disease [40]. It was also shown that smaller fat compartments such as neck fat are subject to independent regulation and that the amount of fat in the renal sinus area is related to proteinuria [41].

Since simple non-invasive methods such as body impedance measurement cannot determine some fat compartments such as visceral fat with sufficient accuracy, MRI with its ability to record volume data sets can also be employed excellently in this area.

\section{Skeletal musculature}

A reduction in the quantity (and in some cases quality) of skeletal muscle is called sarcopenia. Especially in older patients, sarcopenia often leads to reduced activity and mobility and can result in loss of independence. Monitoring muscle build-up also plays a role in training after immobilisation due to illness or in sports medicine. Depending on the region of interest, cross-sectional areas of muscles or entire volumes can be quantitatively assessed by CT or MRI [42].

\section{Discussion}

MRI is very well suited to quantitatively investigate anatomical structures in high-resolution 3D image datasets, both in terms of their size and volume (Fig. 1) as well as their signal properties. The alternative method CT is unfortunately associated with a radiation exposure that can hardly be justified when examining volunteers, and 3D ultrasound examinations are currently not readily possible for all anatomic structures in the body trunk, since air and bone-containing areas are not penetrable for ultrasound and the tissue contrasts are often critical for automatic evaluation.

As MRI is generally not associated with harmful effects on tissue, this method is also particularly well suited for examinations of large, mainly healthy cohorts, although this is relatively cost-intensive. The determination of organ volumes and fat volumes in large cohorts with healthy individuals from different age groups and genders allows the determination of normal value ranges, so that results of later individual examinations can be better assessed. However, systematic errors due to the use of different recording or image analysis methods must be taken into account.

In large cohorts from the entire population, individuals with diseases and/or medications are included, so that previously unknown correlations can also be recognised and further elucidated (in analogy to work on the brain as [43]). This allows new pathomechanisms to be detected and existing hypotheses to be tested. Since random correlations sometimes occur with a large number of parameters under investigation, careful statistical analysis (with Bonferroni correction) and the verification of results in independent collectives are indispensable.

\section{Individual studies}

The question arises: is every size specification of an organ or its substructures relevant? For most questions this is probably not the case, at least as long as the measured values are in the "normal range". Significant deviations from the normal range, however, can indicate pathological processes as reported above or confirm already existing suspected diagnoses. It should also be noted that experienced radiologists will often notice significant deviations of the organ size from the normal range when reviewing the images, even without automated assessment.

Visceral and epi-/pericardial fat volumes in particular, along with other conditions, are considered risk factors for the development of diabetes and cardiovascular disease. A determination of the volume as well as therapeutic measures to reduce those fat compartments is, therefore, useful. Individual measurement of fat volume reduction is often very helpful in motivating patients when implementing appropriate therapies; if, for example, muscle mass increases and fat mass decreases during a lifestyle intervention with more physical activity, this is not visible through simple weight or whole body impedance measurements. In those cases, corresponding efforts are discontinued if no positive encouragement is given through a demonstrable success. The same holds true for monitoring the strengthening of the skeletal muscles through training after immobilisation due to illness or in the field of sports.

With the rapid development of automatic segmentation methods using IA algorithms, it is quite conceivable that MRI (and possibly clinically indicated CT) examinations of the body trunk will in future allow organ volumes and other quantitative measurements to be determined automatically. Similar to the routine laboratory chemical analysis of blood and other body fluids, deviations from the normal range will then be indicated and can be exploited to make a diagnosis.

Funding Open Access funding enabled and organized by Projekt DEAL. Deutsche Forschungsgemeinschaft, SPP 2177 Radiomics: next Generation of Biomedical Imaging, Fritz Schick.

\section{Declarations}

Conflict of interest The author declares that he have no conflict of interest.

Ethical approval this study does not contain any studies with human participants or animals. 
Open Access This article is licensed under a Creative Commons Attribution 4.0 International License, which permits use, sharing, adaptation, distribution and reproduction in any medium or format, as long as you give appropriate credit to the original author(s) and the source, provide a link to the Creative Commons licence, and indicate if changes were made. The images or other third party material in this article are included in the article's Creative Commons licence, unless indicated otherwise in a credit line to the material. If material is not included in the article's Creative Commons licence and your intended use is not permitted by statutory regulation or exceeds the permitted use, you will need to obtain permission directly from the copyright holder. To view a copy of this licence, visit http://creativecommons.org/licenses/by/4.0/.

\section{References}

1. Keil B, Wald LL (2013) Massively parallel MRI detector arrays. J Magn Reson 229:75-89

2. Feng L, Benkert T, Block KT, Sodickson DK, Otazo R, Chandarana H (2017) Compressed sensing for body MRI. J Magn Reson Imaging 45(4):966-987

3. Bipin Mehta B, Coppo S, Frances McGivney D, Ian Hamilton J, Chen Y, Jiang Y, Ma D, Seiberlich N, Gulani V, Alan Griswold M (2019) Magnetic resonance fingerprinting: a technical review. Magn Reson Med 81(1):25-46

4. O'Connor JP, Jackson A, Asselin MC, Buckley DL, Parker GJ, Jayson GC (2008) Quantitative imaging biomarkers in the clinical development of targeted therapeutics: current and future perspectives. Lancet Oncol 9(8):766-776

5. Wang L, Chitiboi T, Meine H, Günther M, Hahn HK (2016) Principles and methods for automatic and semi-automatic tissue segmentation in MRI data. MAGMA 29(2):95-110

6. Lee B, Yamanakkanavar N, Choi JY (2020) Automatic segmentation of brain MRI using a novel patch-wise U-net deep architecture. PLoS ONE 15(8):e0236493

7. Bycroft C, Freeman C, Petkova D, Band G, Elliott LT, Sharp K, Motyer A, Vukcevic D, Delaneau O, O'Connell J, Cortes A, Welsh S, Young A, Effingham M, McVean G, Leslie S, Allen N, Donnelly P, Marchini J (2018) The UK Biobank resource with deep phenotyping and genomic data. Nature 562(7726):203-209

8. Bamberg F, Kauczor HU, Weckbach S, Schlett CL, Forsting M, Ladd SC, Greiser KH, Weber MA, Schulz-Menger J, Niendorf T, Pischon T, Caspers S, Amunts K, Berger K, Bülow R, Hosten N, Hegenscheid K, Kröncke T, Linseisen J, Günther M, Hirsch JG, Köhn A, Hendel T, Wichmann HE, Schmidt B, Jöckel KH, Hoffmann W, Kaaks R, Reiser MF, Völzke H (2015) Whole-body MR imaging in the german national cohort: rationale, design, and technical background. Radiology 277(1):206-220

9. Tosun D, Rettmann ME, Han X, Tao X, Xu C, Resnick SM, Pham DL, Prince JL (2004) Cortical surface segmentation and mapping. Neuroimage 23(1):S108-s118

10. Giorgio A, De Stefano N (2013) Clinical use of brain volumetry. J Magn Reson Imaging 37(1):1-14

11. Zhao W, Luo Y, Zhao L, Mok V, Su L, Yin C, Sun Y, Lu J, Shi L, Han Y (2019) Automated brain MRI volumetry differentiates early stages of alzheimer's disease from normal aging. J Geriatr Psychiatry Neurol 32(6):354-364

12. Heckemann RA, Hammers A, Rueckert D, Aviv RI, Harvey CJ, Hajnal JV (2008) Automatic volumetry on MR brain images can support diagnostic decision making. BMC Med Imaging 8:9

13. Deshmukh S, Rubesova E, Barth R (2010) MR assessment of normal fetal lung volumes: a literature review. AJR Am J Roentgenol 194(2):W212-217
14. Ruppel GL (2012) What is the clinical value of lung volumes? Respir Care 57(1):26-35

15. Scardulla F, Rinaudo A, Pasta S, Scardulla C (2016) Evaluation of ventricular wall stress and cardiac function in patients with dilated cardiomyopathy. Proc Inst Mech Eng H 230(1):71-74

16. Scatteia A, Baritussio A, Bucciarelli-Ducci C (2017) Strain imaging using cardiac magnetic resonance. Heart Fail Rev 22(4):465-476

17. Küstner T, Bustin A, Jaubert O, Hajhosseiny R, Masci PG, Neji R, Botnar R, Prieto C (2021) Fully self-gated free-running 3D Cartesian cardiac CINE with isotropic whole-heart coverage in less than 2 min. NMR Biomed 34(1):e4409

18. Penso M, Moccia S, Scafuri S, Muscogiuri G, Pontone G, Pepi M, Caiani EG (2021) Automated left and right ventricular chamber segmentation in cardiac magnetic resonance images using dense fully convolutional neural network. Comput Methods Programs Biomed 204:106059

19. Vauthey JN, Abdalla EK, Doherty DA, Gertsch P, Fenstermacher MJ, Loyer EM, Lerut J, Materne R, Wang X, Encarnacion A, Herron D, Mathey C, Ferrari G, Charnsangavej C, Do KA, Denys A (2002) Body surface area and body weight predict total liver volume in Western adults. Liver Transpl 8(3):233-240

20. Feng LM, Wang PQ, Yu H, Chen RT, Wang J, Sheng X, Yuan ZL, Shi PM, Xie WF, Zeng X (2017) New formula for predicting standard liver volume in Chinese adults. World J Gastroenterol 23(27):4968-4977

21. Kromrey ML, Ittermann T, Wahsen C, Plodeck V, Seppelt D, Hoffmann RT, Heiss P, Kühn JP (2018) Reference values of liver volume in Caucasian population and factors influencing liver size. Eur J Radiol 106:32-37

22. Gotra A, Sivakumaran L, Chartrand G, Vu KN, VandenbrouckeMenu F, Kauffmann C, Kadoury S, Gallix B, de Guise JA, Tang A (2017) Liver segmentation: indications, techniques and future directions. Insights Imaging 8(4):377-392

23. Bongers MN, Stefan N, Fritsche A, Häring HU, Nikolaou K, Schick F, Machann J (2015) Liver volume, intrahepatic fat and body weight in the course of a lifestyle interventional study: analysis with quantitative MR-based methods. Radiologe 55(4):323-328

24. Park HJ, Kim KW, Lee J, Park T, Kwon HJ, Song GW, Lee SG (2021) Change in hepatic volume profile in potential live liver donors after lifestyle modification for reduction of hepatic steatosis. Abdom Radiol (NY) 46(8):3877-3888

25. Lim MC, Tan CH, Cai J, Zheng J, Kow AW (2014) CT volumetry of the liver : where does it stand in clinical practice? Clin Radiol 69(9):887-895

26. Pickhardt PJ, Malecki K, Hunt OF, Beaumont C, Kloke J, Ziemlewicz TJ, Lubner MG (2017) Hepatosplenic volumetric assessment at MDCT for staging liver fibrosis. Eur Radiol 27(7):3060-3068

27. Suttorp M, Classen CF (2021) Splenomegaly in children and adolescents. Front Pediatr 9:704635

28. Williams JM, Hilmes MA, Archer B, Dulaney A, Du L, Kang H, Russell WE, Powers AC, Moore DJ, Virostko J (2020) Repeatability and reproducibility of pancreas volume measurements using MRI. Sci Rep 10(1):4767

29. Burute N, Nisenbaum R, Jenkins DJ, Mirrahimi A, Anthwal S, Colak E, Kirpalani A (2014) Pancreas volume measurement in patients with type 2 diabetes using magnetic resonance imagingbased planimetry. Pancreatology 14(4):268-274

30. Turkdogan FT, Ertekin E, Tuncyurek O, Dagli B, Canakci SE, Ture M, Turkdogan KA (2020) A new method: measurement of pancreas volume in computerised tomography as a diagnostic guide for acute pancreatitis. J Pak Med Assoc 70(8):1408-1412

31. DeSouza SV, Priya S, Cho J, Singh RG, Petrov MS (2019) Pancreas shrinkage following recurrent acute pancreatitis: an MRI study. Eur Radiol 29(7):3746-3756 
32. Sequeiros IM, Hester K, Callaway M, Williams A, Garland Z, Powell T, Wong FS, Jarad NA (2010) MRI appearance of the pancreas in patients with cystic fibrosis: a comparison of pancreas volume in diabetic and non-diabetic patients. Br J Radiol 83(995):921-926

33. Asaturyan H, Thomas EL, Bell JD, Villarini B (2019) A framework for automatic morphological feature extraction and analysis of abdominal organs in MRI volumes. J Med Syst 43(12):334

34. Wang X, Vrtiska TJ, Avula RT, Walters LR, Chakkera HA, Kremers WK, Lerman LO, Rule AD (2014) Age, kidney function, and risk factors associate differently with cortical and medullary volumes of the kidney. Kidney Int 85(3):677-685

35. Will S, Martirosian P, Würslin C, Schick F (2014) Automated segmentation and volumetric analysis of renal cortex, medulla, and pelvis based on non-contrast-enhanced T1- and T2-weighted MR images. MAGMA 27(5):445-454

36. Roseman DA, Hwang SJ, Oyama-Manabe N, Chuang ML, O'Donnell CJ, Manning WJ, Fox CS (2017) Clinical associations of total kidney volume: the framingham heart study. Nephrol Dial Transplant 32(8):1344-1350

37. Magistroni R, Corsi C, Martí T, Torra R (2018) A review of the imaging techniques for measuring kidney and cyst volume in establishing autosomal dominant polycystic kidney disease progression. Am J Nephrol 48(1):67-78

38. Piché ME, Poirier P, Lemieux I, Després JP (2018) Overview of epidemiology and contribution of obesity and body fat distribution to cardiovascular disease: an update. Prog Cardiovasc Dis 61(2):103-113

39. Machann J, Stefan N, Wagner R, Fritsche A, Bell JD, Whitcher B, Häring HU, Birkenfeld AL, Nikolaou K, Schick F, Thomas EL
(2020) Normalized indices derived from visceral adipose mass assessed by magnetic resonance imaging and their correlation with markers for insulin resistance and prediabetes. Nutrients 12(7):2064

40. Sinha SK, Thakur R, Jha MJ, Goel A, Kumar V, Kumar A, Mishra V, Varma CM, Krishna V, Singh AK, Sachan M (2016) Epicardial adipose tissue thickness and its association with the presence and severity of coronary artery disease in clinical setting: a crosssectional observational study. J Clin Med Res 8(5):410-419

41. Wagner R, Machann J, Lehmann R, Rittig K, Schick F, Lenhart J, Artunc F, Linder K, Claussen CD, Schleicher E, Fritsche A, Häring HU, Weyrich P (2012) Exercise-induced albuminuria is associated with perivascular renal sinus fat in individuals at increased risk of type 2 diabetes. Diabetologia 55(7):2054-2058

42. Faron A, Sprinkart AM, Kuetting DLR, Feisst A, Isaak A, Endler C, Chang J, Nowak S, Block W, Thomas D, Attenberger U, Luetkens JA (2020) Body composition analysis using CT and MRI: intra-individual intermodal comparison of muscle mass and myosteatosis. Sci Rep 10(1):11765

43. Akoudad S, Portegies ML, Koudstaal PJ, Hofman A, van der Lugt A, Ikram MA, Vernooij MW (2015) Cerebral microbleeds are associated with an increased risk of stroke: the rotterdam study. Circulation 132(6):509-516

Publisher's Note Springer Nature remains neutral with regard to jurisdictional claims in published maps and institutional affiliations. 